Results There was no evidence of increased quantities of muscle nuclear P65 or P50 binding DNA in patients compared with controls and the quantity of muscle nuclear AP-1 c-jun binding DNA was lower in patients than controls $(336(174,513)$ RLU vs $508(284,846)$ RLU, $p=0.01$ ). Patients with low FFMI ( $\leq 15$ and $16 \mathrm{~kg} / \mathrm{m}^{2}$ for females and males respectively, $\mathrm{n}=54$ ) did not have increased quantities of P65, P50 or c-jun binding DNA compared with patients with normal FFMI ( $\mathrm{n}=60$, (286 (171,407) vs $260(176,376)$ RLU $\mathrm{p}=0.94,880(400,1373)$ vs $1064(654,1586)$ RLU $p=0.33$ and 313 $(155,484)$ vs $353(181,570)$ RLU $p=0.42$ respectively). There were no correlations between quantities of the transcription factors binding DNA and quadriceps type I or II fibre CSA or type I, IIa or IIx fibre proportions.

Conclusion NF- $\kappa \mathrm{B}$ and AP-1 DNA-binding were not increased in the quadriceps of patients with stable COPD compared to controls and did not predict reduced FFMI or quadriceps fibre size, nor quadriceps fibre proportions, in patients.

\section{P144 MUSCLE FIBRE ATROPHY AND AEROBIC TO ANAEROBIC FIBRE TYPE SHIFT IN THE QUADRICEPS IN COPD}

doi:10.1136/thx.2010.150987.45

${ }^{1} \mathrm{~S}$ A Natanek, ${ }^{1} \mathrm{H}$ R Gosker, ${ }^{2} \mathrm{~S}$ Slot, ${ }^{1} \mathrm{G}$ S Marsh, ${ }^{2} \mathrm{R}$ C J Langen, ${ }^{1} \mathrm{~N}$ S Hopkinson, ${ }^{1}$ W D-C Man, ${ }^{3} \mathrm{~J}$ Moxham, ${ }^{4} \mathrm{P}$ R Kemp, ${ }^{2} \mathrm{~A}$ M W J Schols, ${ }^{1} \mathrm{M}$ I Polkey. ${ }^{1} \mathrm{~N} I H R$ Respiratory Biomedical Research Unit of the Royal Brompton and Harefield NHS Foundation Trust and National Heart \& Lung Institute, Imperial College London, London, UK; ${ }^{2}$ NUTRIM School for Nutrition, Toxicology \& Metabolism, Maastricht University, Maastricht, the Netherlands; ' ${ }^{G}$ uy's, King's and Thomas' School of Medicine, London, UK; ${ }^{4}$ Molecular Medicine Section, National Heart \& Lung Institute, Imperial College London, London, UK

Introduction Quadriceps dysfunction is associated with reduced exercise tolerance and survival in COPD. Quadriceps dysfunction has been attributed to quadriceps fibre atrophy (FA) and oxidative to glycolytic (type I to II) fibre shift (FS) but the prevalence of FA and FS and their individual relationships with exercise capacity are not clear.

Methods We measured lung function, physical activity, fat-free mass index (FFMI), quadriceps strength and endurance and exercise performance (6-min walk and incremental cycle ergometry) in 114 COPD patients and 30 healthy age-matched controls and measured mid-thigh muscle cross-sectional area (MTCSA) by CT in 30 patients and 10 controls. Each subject had a quadriceps biopsy and type I, IIa and IIx fibre proportions and CSA were determined by immunohistochemistry. FA and FS were defined using reference intervals for quadriceps fibre characteristics derived from the controls.

Results $24 \%$ of patients had quadriceps fibre characteristics within normal limits, 31\% had isolated FS, 20\% had isolated FA (predominantly type II FA) and 25\% had both FS and FA. Muscle FA could not be discerned by FFMI, MT $\mathrm{CSA}_{\mathrm{A}}$ or quadriceps strength values. Patients with isolated FS had a poorer exercise performance than patients with normal fibres $(6 \mathrm{MW} \%$ predicted $66(46,82)$ vs 77 $(63,95), \mathrm{p}=0.025$ and peak $\mathrm{VO}_{2} \%$ predicted $41(28,48)$ vs $50(38,58)$, $\mathrm{p}=0.008)$, patients with isolated FA $(6 \mathrm{MW} \%$ predicted $66(46,82)$ vs $91(70,103), \mathrm{p}=0.001$ and peak $\mathrm{VO}_{2} \%$ predicted $41(28,48) \mathrm{v} 49$ $(39,62), p=0.006)$ and patients with both FS and FA (6MW \% predicted $66(46,82)$ vs $79(63,89), p=0.01)$. Patients with isolated FA or both FS and FA did not have a reduced exercise performance vs patients with normal muscle $(6 \mathrm{MW} \%$ predicted $\mathrm{p}=0.14$ and 0.53 and peak $\mathrm{VO}_{2} \%$ predicted $\mathrm{p}=0.98$ and $\mathrm{FA}$ vs normal and FS plus FA vs normal respectively). Stepwise multiple regression confirmed that type I fibre proportion was a positive predictor and type IIa fibre CSA was a negative predictor of $6 \mathrm{MW}$ and cycle performance in patients, independent of lung function impairment.

Conclusion Quadriceps FA and FS do not necessarily co-occur in COPD. FS is associated with impaired exercise tolerance whereas FA is associated with preserved exercise capacity in COPD.

\section{P145 EVALUATION OF A QUADRICEPS MUSCLE ENDURANCE LEG LIFT TEST IN PATIENTS WITH CHRONIC OBSTRUCTIVE PULMONARY DISEASE}

doi:10.1136/thx.2010.150987.46

${ }^{1} \mathrm{~S}$ Hattle, ${ }^{1} \mathrm{C}$ Hayton, ${ }^{1} \mathrm{~J}$ Elia, ${ }^{2} \mathrm{~A} \mathrm{M}$ Wilson. ${ }^{1}$ Norfolk and Norwich University Hospital, Norwich, UK; ${ }^{2}$ University of East Anglia, Norwich, UK

Introduction and objectives Quadriceps muscle strength is commonly used to assess patients with chronic obstructive pulmonary disease (COPD). However a simple endurance test is not routinely available. We wished to evaluate a simple test of muscle endurance.

Methods We developed a quadriceps muscle leg lift test whereby seated patients extended their dominant leg from $90^{\circ}$ flexion to $0^{\circ}$ flexion for $5 \mathrm{~s}$ with a weight ( $2 \mathrm{~kg}$ for Men and $1 \mathrm{~kg}$ for women) strapped to their ankle. They repeated cycles of flexion and extension (with $5 \mathrm{~s}$ hold at each extension) until exhaustion. The duration of this test and number of lifts was compared to the duration and distance walked during an endurance shuttle walk test (at the speed equivalent to $85 \%$ of maximum oxygen uptake as determined from an incremental shuttle walk test), muscle strength (using an dynometer) and the dyspnoea and fatigue domains of the Chronic Respiratory Questionnaire (CRQ).

Results 43 (30 Males) patients with COPD with mean (standard deviation) of 68.9 (9.3) years and forced expiratory volume in $1 \mathrm{~s}$ $\left(\mathrm{FEV}_{1}\right)$ of 42.5 (13.8) percent of predicted normal completed the tests. The mean (standard deviation) quadriceps strength was 16.1 (5.0) $\mathrm{kg}$, number of lifts was 12.5 (7.1) in 85.2 (48.3) s, endurance shuttle-walk test (ESWT) distance was 177.3 (89.8) $\mathrm{m}$ in 184.7 (88.8) s and dyspnoea and fatigue domains of the CRQ were 2.4 (1.1) and 3.3 (1.2) respectively. The correlation coefficients comparing the measures are shown in Abstract P145 Table 1.

Conclusion The endurance leg lift test was closely associated with the fatigue domain of the Chronic Respiratory Questionnaire but poorly associated with the dyspnoea domain. This new test may have some clinical utility given that it more closely relates to fatigue than either muscle strength or the endurance shuttle-walk test.

\section{Abstract P145 Table 1}

\begin{tabular}{llclll}
\hline & $\begin{array}{l}\text { Quadriceps } \\
\text { strength }\end{array}$ & $\begin{array}{l}\text { Leg lifts } \\
\text { number }\end{array}$ & $\begin{array}{l}\text { Leg lifts } \\
\text { duration }\end{array}$ & $\begin{array}{l}\text { ESWT } \\
\text { distance }\end{array}$ & ESWT- duration \\
\hline Quadriceps strength & 1.000 & 0.219 & 0.129 & 0.067 & 0.062 \\
Leg lifts-number & 0.219 & 1.000 & 0.967 & 0.165 & 0.100 \\
Leg lifts-duration & 0.129 & 0.967 & 1.000 & 0.226 & 0.194 \\
ESWT-distance & 0.067 & 0.165 & 0.226 & 1.000 & 0.691 \\
ESWT-duration & 0.062 & 0.100 & 0.194 & 0.691 & 1.000 \\
CRQ-dyspnoea & 0.111 & -0.079 & 0.015 & 0.325 & 0.226 \\
CRQ-fatigue & 0.243 & 0.361 & 0.552 & 0.302 & 0.161 \\
\hline
\end{tabular}

